\title{
Air pollutants and outpatient visits for cardiovascular disease in a severe haze-fog city: Shijiazhuang, China
}

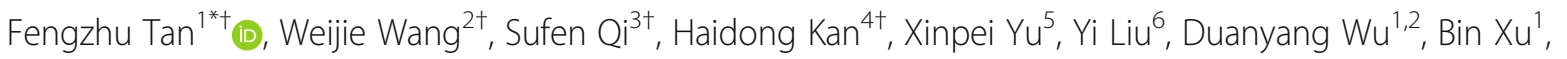
Fan Meng ${ }^{1}$ and Sicen Liu ${ }^{1}$

\begin{abstract}
Background: Many studies have reported the impact of air pollution on cardiovascular disease (CVD), but few of these studies were conducted in severe haze-fog areas. The present study focuses on the impact of different air pollutant concentrations on daily CVD outpatient visits in a severe haze-fog city.

Methods: Data regarding daily air pollutants and outpatient visits for CVD in 2013 were collected, and the association between six pollutants and CVD outpatient visits was explored using the least squares mean (LSmeans) and logistic regression. Adjustments were made for days of the week, months, air temperature and relative humidity.

Results: The daily CVD outpatient visits for particulate matter $\left(\mathrm{PM}_{10}\right.$ and $\left.\mathrm{PM}_{2.5}\right)$, sulphur dioxide $\left(\mathrm{SO}_{2}\right)$, nitrogen dioxide $\left(\mathrm{NO}_{2}\right)$, carbon monoxide $(\mathrm{CO})$, and ozone $\left(\mathrm{O}_{3}\right)$ in the 90th-quantile group were increased by 30.01, $29.42,17.68,14.98,29.34 \%$, and $-19.87 \%$, respectively, compared to those in the $<10$ th-quantile group. Odds ratios (ORs) and 95\% confidence intervals (Cls) for the increase in daily CVD outpatient visits in $\mathrm{PM}_{10}$ 300- and $500-\mu \mathrm{g} / \mathrm{m}^{3}, \mathrm{PM}_{2.5} 100-$ and $300-\mu \mathrm{g} / \mathrm{m}^{3}$ and $\mathrm{CO} 3-\mathrm{mg} / \mathrm{m}^{3}$ groups were $2.538(1.070-6.020), 7.781(1.681-36.024)$, 3.298 (1.559-6.976), $8.72(1.523-49.934)$, and $5.808(1.016-33.217)$, respectively, and their corresponding attributable risk percentages (AR\%) were $60.6,87.15,69.68,88.53$ and $82.78 \%$, respectively. The strongest associations for $\mathrm{PM}_{10}, \mathrm{PM}_{2.5}$ and $\mathrm{CO}$ were found only in lag 0 and lag 1. The ORs for the increase in CVD outpatient visits per increase in different units of the six pollutants were also analysed.

Conclusions: All five air pollutants except $\mathrm{O}_{3}$ were positively associated with the increase in daily CVD outpatient visits in lag 0 . The high concentrations of $\mathrm{PM}_{10}, \mathrm{PM}_{2.5}$ and $\mathrm{CO}$ heightened not only the percentage but also the risk of increased daily CVD outpatient visits. $\mathrm{PM}_{10}, \mathrm{PM}_{2.5}$ and $\mathrm{CO}$ may be the main factors of CVD outpatient visits.
\end{abstract}

Keywords: Air pollution, Cardiovascular disease, Outpatient visits, Particulate matter, Sulphur dioxide, Nitrogen dioxide, Carbon monoxide

\footnotetext{
* Correspondence: fengzhutan@outlook.com; 1250324286@qq.com

${ }^{\dagger}$ Fengzhu Tan, Weijie Wang, Sufen Qi, Haidong Kan, The first four authors should be regarded as joint First Authors.

${ }^{1}$ Department of Environmental and Occupational Health, School of Public Health, Hebei Medical University, 361 Zhongshan East Road, Shijiazhuang 050017, Hebei, China

Full list of author information is available at the end of the article
}

(c) The Author(s). 2019 Open Access This article is distributed under the terms of the Creative Commons Attribution 4.0 International License (http://creativecommons.org/licenses/by/4.0/), which permits unrestricted use, distribution, and reproduction in any medium, provided you give appropriate credit to the original author(s) and the source, provide a link to the Creative Commons license, and indicate if changes were made. The Creative Commons Public Domain Dedication waiver (http://creativecommons.org/publicdomain/zero/1.0/) applies to the data made available in this article, unless otherwise stated. 


\section{Background}

Over the past several decades, air pollution has been thought to have adverse effects on public health. Many epidemiological studies have revealed that primary ambient air pollutants, including $\mathrm{PM}_{2.5}, \mathrm{PM}_{10}, \mathrm{NO}_{2}, \mathrm{SO}_{2}, \mathrm{O}_{3}$ and $\mathrm{CO}$, increase the risk of hospital admission and mortality for CVD [1-9]. Exposure to air pollutants, except for $\mathrm{O}_{3}$, was strongly associated with acute cardiovascular events such as myocardial infarction, heart failure and arrhythmia [10, 11]. Only one study has shown that acute controlled exposure to air pollutants did not increase the short-term risk of arrhythmia in participants [12]. Analytical methods as time series analysis, generalized additive models and case-crossover were used to estimate the adverse effects of air pollutants on the hospitalization and mortality of CVD in some studies in the United States, Canada, the United Kingdom and the moderately polluted areas of China (e.g., Shanghai: the average $\mathrm{PM}_{10}$ and $\mathrm{PM}_{2.5}$ were, respectively, $81.7 \mu \mathrm{g} / \mathrm{m}^{3}$ and $38.6 \mu \mathrm{g} / \mathrm{m}^{3}$ ) [3, 4, 13, 14]. $\mathrm{PM}_{2.5}$ in developed countries is relatively low (median $15 \mu \mathrm{g} / \mathrm{m}^{3}$ ), but $\mathrm{PM}_{2.5}$ in some cities in developing countries is likely to be up to 10-fold higher than the US National Ambient Air Quality Standards. New Delhi in India and Beijing in China have daily $\mathrm{PM}_{2.5}$ concentrations of $100-300 \mu \mathrm{g} / \mathrm{m}^{3}$. More high-quality studies are urgently needed to establish the effect of air pollution on heart failure outcomes in developing countries [10].

In 2013, severe haze-fog events occurred frequently in northern China and were more concentrated in some cities in Hebei Province around Beijing. However, the acute impact of air pollutants on CVD in these severe haze-fog areas has rarely been reported. In addition, it seems unsuitable to assess the impact of $\mathrm{PM}_{2.5}$ on CVD in these severe haze-fog areas using the methods (e.g., only evaluating the impact of $\mathrm{PM}_{2.5}$ per $10-\mu \mathrm{g} / \mathrm{m}^{3}$ increase) used in developed countries or in lightly or mildly polluted areas because the $\mathrm{PM}_{2.5}$ daily average concentration (sometimes up to $500 \mu \mathrm{g} / \mathrm{m}^{3}$ ) or annual average concentration in developing countries was much higher than in developed countries. Therefore, it is necessary to identify new methods to explore or explain the relationship between short-term exposure to air pollutants and outpatient visits or hospitalization for CVD in these severe haze-fog areas.

Based on the above, we hypothesize that the relationship between daily CVD outpatient visits and air pollutants in the severe haze-fog areas in developing countries should differ from this relationship in moderately or slightly polluted areas in developed countries. Therefore, we focused on the concentration-impact relationship between the different daily concentrations of air pollutants and the daily number of CVD outpatient visits (i.e., evaluating the impact of air pollutants by calculating
ORs of different concentrations, not merely by calculating the ORs of each $10-\mu \mathrm{g} / \mathrm{m}^{3}$ increase). Our results will provide an early warning reference for managers in hospitals and in the Centers for Disease Control and Prevention during the occurrence of persistent severe haze-fog.

\section{Methods}

Study design and data collection

Shijiazhuang belongs to the region of Beijing-TianjinHebei (BTH) and was one of 10 most heavily polluted cities in 2013 in China, where the median daily concentrations for $\mathrm{PM}_{10}$ and $\mathrm{PM}_{2.5}$ were up to $287 \mu \mathrm{g} / \mathrm{m}^{3}$ and $123 \mu \mathrm{g} / \mathrm{m}^{3}$, respectively. The data on average concentrations of six daily air pollutants $\left(\mathrm{PM}_{10}, \mathrm{PM}_{2.5}, \mathrm{SO}_{2}, \mathrm{NO}_{2}\right.$, $\mathrm{O}_{3}$ and $\mathrm{CO}$ ) were from the national environmental monitoring points in Shijiazhuang. Daily meteorological data (air temperature and relative humidity) were provided by Beijing's National Meteorological Center. The data for daily outpatient visits (including emergency room patients) for CVD were collected from the four branch hospitals of two affiliated hospitals of Hebei Medical University, where all electronic medical records were classified according to the International Classification of Diseases (10th Revision) and each patient had a complete medical record (e.g., name, sex, region for patients; department for diagnosis, disease type, disease name, and ICD code). We chose the outpatients in ICD10 codes I00-I99, including CVD, such as angina, arrhythmia, heart failure, and myocardial infarction. All CVD outpatients were identified by two data collectors. We only collected outpatient data that was not related to personal privacy (i.e., de-identification data that did not include personal name, gender, ethnicity, body weight, etc.) and the study protocol was approval by Medical Ethics Committee in Hebei Medical University. The network technology has been widely put into use in 2013, and ICD coding records for outpatient visits in the hospitals were more functional than ever, which helped us to correctly choose the CVD outpatients. All data were collected from January 1 to December 31, 2013.

\section{Variables and statistical analysis}

We obtained the least squares mean (LSmeans) of daily CVD outpatient visits in every decile group of each air pollutant using a general linear model (GLM of SAS) to better understand and explore the relationship between the daily concentration of six air pollutants (independent variables) and the daily amount of CVD outpatient visits (dependent variables). The difference between the LSmeans of CVD in the 10 quantile groups of each air pollutant was also tested. Based on the LSmeans, we calculated the increased percentage of daily CVD 
outpatient visits in 9 quantile groups of each air pollutant decile compared with the $<10$ th-quantile group.

Non-conditional logistic regression was used to calculate ORs and 95\% CIs to further evaluate the risk of the increase of CVD outpatient visits in different concentrations and lag days for each pollutant. Based on the above LSmeans results of CVD outpatient visits, the concentration of each air pollutant was re-grouped. The lowest concentration of each air pollutant was used as a reference level for calculating $\mathrm{OR}$, for which concentrations for $\mathrm{PM}_{10}, \mathrm{PM}_{2.5}, \mathrm{CO}, \mathrm{SO}_{2}$ and $\mathrm{NO}_{2}$ were $<200 \mu \mathrm{g} / \mathrm{m}^{3},<100 \mu \mathrm{g} / \mathrm{m}^{3},<1 \mathrm{mg} / \mathrm{m}^{3},<50 \mu \mathrm{g} / \mathrm{m}^{3}$ and $<40 \mu \mathrm{g} / \mathrm{m}^{3}$, respectively. If the number of daily CVD outpatient visits was $>285$ (i.e., more than average of one year), the amount of daily CVD outpatient visits was considered to have increased (i.e., more than average), which was considered to be a threshold for the increase in daily CVD outpatient visits); in contrast, if the number of daily CVD outpatient visits was $\leq 285$, it was considered to show no increase (i.e., considered to be the usual number of daily CVD outpatient visits). Moreover, we first analysed LSmeans of daily CVD outpatient visits at the same concentrations before calculating the above ORs, which would allow LSmeans and ORs to support or confirm each other.

We also analysed the following: the decile concentration values of each pollutant (supplemental files for the above content); the ORs and 95\% CIs for CVD outpatient visits per increase in different unit of each pollutant; and the Pearson partial correlation coefficient between CVD outpatient visits and air pollutants on different lag days.

Regarding the confounding factors, we considered the results of preliminary analysis (the amount of CVD outpatient visits decreased along with air temperature increasing, but air humidity had no such impact) in our data on the one hand; on the other hand, referencing the results of other similar studies, days of the week, months, daily air temperature and relative humidity (the air temperature and humidity were also divided into ten groups by decile and then adjusted) were identified as confounding factors. These confounders were adjusted in all the above analyses (LSmeans, ORs, and Pearson partial correlation coefficient). However, the flu was not adjusted for because the proportion of flu outpatient visits in northern China in 2013 did not exceed the highest level in the 5 years before 2013 [15].

In addition, descriptive analysis, cluster analysis and other basic analyses were also performed prior to the above analyses to understand the characteristics of air pollutants or CVD outpatient visits and the confounding factors to be adjusted. These analyses showed that $\mathrm{O}_{3}$ did not belong to the same category of variables as $\mathrm{PM}_{10}, \mathrm{PM}_{2.5}, \mathrm{SO}_{2}, \mathrm{NO}_{2}$, and $\mathrm{CO}$ and was negatively related to CVD outpatient visits; thus, the $\mathrm{O}_{3}$ data from 183 days of the warm period (16 April to 15 October) were analysed as well.

A flow diagram for statistical analyses was provided in Additional file 1: Figure S1. All statistical analyses were performed using SAS software (SAS Institute Inc. Contract Site Number: 553024). A $P$ value $<0.05$ was considered statistically significant.

\section{Results}

\section{LSmeans of daily CVD outpatient visits}

Table 1 provides the LSmeans of daily CVD outpatient visits in the different quantile groups of air pollutants in Lag 0. The LSmeans of the $\mathrm{PM}_{10}$ 50th group, the $\mathrm{PM}_{2.5}$ 40th group, the $\mathrm{SO}_{2}$ and $\mathrm{NO}_{2}$ 70th group, and the $\mathrm{CO}$ 80th group began to be higher than those of other groups (all $P<0.05$ ). However, $\mathrm{O}_{3}$ showed a negative relationship with daily CVD outpatient visits, which was

Table 1 Daily outpatient visits for cardiovascular disease in different decile groups for air pollutants in lag 0

\begin{tabular}{|c|c|c|c|c|c|c|c|}
\hline \multirow{2}{*}{$\begin{array}{l}\text { Decile } \\
\text { groups }\end{array}$} & \multicolumn{7}{|c|}{ Daily outpatient visits ${ }^{a}$} \\
\hline & $\mathrm{PM}_{10}$ & $\mathrm{PM}_{2.5}$ & $\mathrm{SO}_{2}$ & $\mathrm{NO}_{2}$ & $\mathrm{CO}$ & $\mathrm{O}_{3}$ & $\mathrm{O}_{3}{ }^{\mathrm{C}}$ \\
\hline$<10$ th- & $244 \pm 10$ & $252 \pm 11$ & $258 \pm 13$ & $266 \pm 10$ & $259 \pm 13$ & $329 \pm 15^{b}$ & $265 \pm 13$ \\
\hline 10th- & $263 \pm 9$ & $242 \pm 9$ & $254 \pm 10$ & $254 \pm 9$ & $256 \pm 9$ & $307 \pm 12^{b}$ & $269 \pm 11$ \\
\hline 20th- & $252 \pm 9$ & $256 \pm 9$ & $261 \pm 10$ & $263 \pm 10$ & $257 \pm 9$ & $284 \pm 9^{b}$ & $247 \pm 11$ \\
\hline 30th- & $259 \pm 9$ & $256 \pm 9$ & $277 \pm 9$ & $271 \pm 8$ & $248 \pm 11$ & $266 \pm 10$ & $246 \pm 11$ \\
\hline 40th- & $271 \pm 9$ & $282 \pm 9^{b}$ & $250 \pm 9$ & $264 \pm 10$ & $259 \pm 8$ & $265 \pm 9$ & $241 \pm 10$ \\
\hline 50th- & $280 \pm 8^{b}$ & $270 \pm 9^{b}$ & $267 \pm 10$ & $267 \pm 9$ & $275 \pm 9$ & $266 \pm 9$ & $259 \pm 11$ \\
\hline 60th- & $273 \pm 9^{b}$ & $286 \pm 9^{b}$ & $271 \pm 10$ & $273 \pm 9$ & $277 \pm 8$ & $253 \pm 10$ & $267 \pm 11$ \\
\hline 70th- & $275 \pm 9^{b}$ & $271 \pm 9^{b}$ & $289 \pm 9^{b}$ & $284 \pm 9^{b}$ & $272 \pm 8$ & $242 \pm 10$ & $254 \pm 10$ \\
\hline 80th- & $294 \pm 9^{b}$ & $287 \pm 9^{b}$ & $294 \pm 11^{b}$ & $278 \pm 10$ & $280 \pm 11^{b}$ & $261 \pm 11$ & $274 \pm 11^{b}$ \\
\hline 90th- & $318 \pm 10^{b}$ & $326 \pm 11^{b}$ & $303 \pm 13^{b}$ & $306 \pm 11^{b}$ & $336 \pm 13^{b}$ & $264 \pm 11$ & $270 \pm 12$ \\
\hline
\end{tabular}

${ }^{a}$ Numbers $w$ ere $L S m e a n s \pm S E$, adjusted for days of the $w$ eek, months, air temperature and relative humidity

bSmeans in these groups $w$ ere signif icantly higher than those in other groups $(P<0.05)$

${ }^{\mathrm{c}}$ Results $\mathrm{f}$ rom the $\mathrm{w}$ arm period (16 April to 15 October, 183 days) 
different from other air pollutants; daily CVD outpatient visits in the 80th group was significantly higher than those in the 40th group only in the warm period (183 days, $P<0.05)$. In addition, the 90th-quantile concentration values for $\mathrm{PM}_{10}, \mathrm{PM}_{2.5}, \mathrm{SO}_{2}, \mathrm{NO}_{2}, \mathrm{CO}, \mathrm{O}_{3}(365$ days) and $\mathrm{O}_{3}$ (183 days) were 4.0, 7.1, 9.1, 2.8, 6.1, 14.4 and 3.6 times the 10th-quantile concentration values, respectively (see Additional file 1: Table S1). Among them, the highest daily average concentrations of $\mathrm{PM}_{10}(990 \mu \mathrm{g} /$ $\left.\mathrm{m}^{3}\right)$ and $\mathrm{PM}_{2.5}\left(751 \mu \mathrm{g} / \mathrm{m}^{3}\right)$ were 6.6 times and 21.5 times the US air quality standard $\left(\mathrm{PM}_{10}=150 \mu \mathrm{g} / \mathrm{m}^{3}, \mathrm{PM}_{2.5}=\right.$ $35 \mu \mathrm{g} / \mathrm{m}^{3}$ ) and 6.6 times and 10.0 times the China air quality standard $\left(\mathrm{PM}_{10}=150 \mu \mathrm{g} / \mathrm{m}^{3}, \mathrm{PM}_{2.5}=75 \mu \mathrm{g} / \mathrm{m}^{3}\right)$. The highest daily average concentration of $\mathrm{PM}_{10}\left(990 \mu \mathrm{g} / \mathrm{m}^{3}\right)$ was 19.8 times the EU air quality standard $\left(\mathrm{PM}_{10}=50 \mu \mathrm{g} /\right.$ $\mathrm{m}^{3}$ ) and one-quarter of the particulates concentration $\left(4460 \mu \mathrm{g} / \mathrm{m}^{3}\right)$ in the London smog incident of 1952. Figure 1 shows the increased percentage of daily CVD outpatient visits in 9 quantile groups of each air pollutant in lag 0 compared with the $<10$ th-quantile group. The increased percentages in the 90th-quantile group for $\mathrm{PM}_{10}$, $\mathrm{PM}_{2.5}, \mathrm{SO}_{2}, \mathrm{NO}_{2}$ and $\mathrm{CO}$ were 30.01, 29.42, 17.68, 14.98 and 29.34\%, respectively. In short, the increase in CVD for $\mathrm{PM}_{10}$ and $\mathrm{PM}_{2.5}$ was higher than that in $\mathrm{SO}_{2}$ and $\mathrm{NO}_{2}$; the increase of CVD for CO was obvious only in the 90thquantile group. Table 1 and Fig. 1 revealed a different relationship between $\mathrm{PM}_{10}$ or $\mathrm{PM}_{2.5}$ concentrations and CVD outpatient visit amount.

\section{Impact of $\mathrm{PM}_{10}$ on CVD outpatient visits}

Figure 2 provides the impact of $\mathrm{PM}_{10}$ at different concentrations $\left(\mu \mathrm{g} / \mathrm{m}^{3}\right)$ and lag days on CVD outpatient visits. In panel $\mathrm{A}$, the LSmeans of lag 0 and 1 in the 500$\mu \mathrm{g} / \mathrm{m}^{3}$ group were higher than those in the other four groups; the LSmeans of lag 0 in the $400-\mu \mathrm{g} / \mathrm{m}^{3}$ and $300-$ $\mu \mathrm{g} / \mathrm{m}^{3}$ groups were higher than those in the $<200-\mu \mathrm{g} /$ $\mathrm{m}^{3}$ group (all $P<0.05$ ). In panel $\mathrm{B}$, the ORs (95\% CIs) of lag 0 in the $200-\mu \mathrm{g} / \mathrm{m}^{3}, 300-\mu \mathrm{g} / \mathrm{m}^{3}, 400-\mu \mathrm{g} / \mathrm{m}^{3}$ and $500-$ $\mu \mathrm{g} / \mathrm{m}^{3}$ groups were $1.113(0.523-2.367), 2.538$ (1.076.02), 2.434 (0.709-8.364) and 7.781 (1.681-36.024), respectively, and their AR\% were 10.15, 60.60, 58.92 and $87.15 \%$, respectively. The OR $(95 \% \mathrm{CI})$ of lag 1 in the $500-\mu \mathrm{g} / \mathrm{m}^{3}$ group was $5.56(1.293-23.899)$, and its AR\% was $82.01 \%$. Whether LSmeans or ORs, the impact of $\mathrm{PM}_{10}$ in the $500-\mu \mathrm{g} / \mathrm{m}^{3}$ group on CVD was obvious in lags 0 and 1 .

\section{Impact of $\mathrm{PM}_{2.5}$ on CVD outpatient visits}

Figure 3 provides the impact of $\mathrm{PM}_{2.5}$ at different concentrations $\left(\mu \mathrm{g} / \mathrm{m}^{3}\right)$ and lag days on CVD outpatient visits. In panel A, the LSmeans of lag 0 in the $300-\mu \mathrm{g} / \mathrm{m}^{3}$ group were higher than those in the other three groups; the LSmeans of lag 0 in the $200-\mu \mathrm{g} / \mathrm{m}^{3}$ and $100-\mu \mathrm{g} / \mathrm{m}^{3}$ groups were higher than those in the $<100-\mu \mathrm{g} / \mathrm{m}^{3}$ group. The LSmeans of lag 1 in the $300-\mu \mathrm{g} / \mathrm{m}^{3}$ and $200-$ $\mu \mathrm{g} / \mathrm{m}^{3}$ groups were higher than those in the $100-\mu \mathrm{g} / \mathrm{m}^{3}$ and $<100-\mu \mathrm{g} / \mathrm{m}^{3}$ groups (all $P<0.05$ ). In panel $\mathrm{B}$, the ORs $\left(95 \%\right.$ CIs) of lag 0 in the $100-\mu \mathrm{g} / \mathrm{m}^{3}, 200-\mu \mathrm{g} / \mathrm{m}^{3}$ and $300-\mu \mathrm{g} / \mathrm{m}^{3}$ groups were $3.298(1.559-6.976), 3.094$ (0.939-10.196) and 8.72 (1.523-49.934), respectively, and their AR\% were 69.68, 67.68 and $88.53 \%$, respectively. Although the ORs of lag 1 were not significant, the ORs showed an increasing trend. The LSmeans of lag 5 in the $300-\mu \mathrm{g} / \mathrm{m}^{3}$ group were significantly higher than those in the $200-\mu \mathrm{g} / \mathrm{m}^{3}$ group, but the OR was not significant. Whether LSmeans or ORs, the impact of $\mathrm{PM}_{2.5}$ in the $300-\mu \mathrm{g} / \mathrm{m}^{3}$ group on CVD was obvious only in lag 0 .

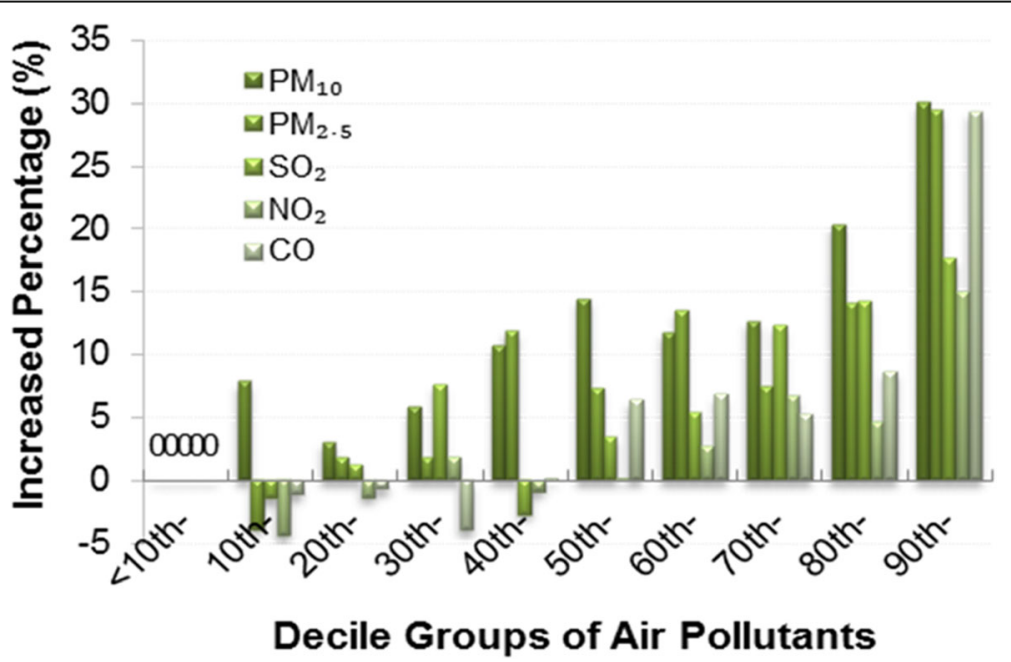

Fig. 1 The increased percentage of daily CVD outpatient visits in nine quantile groups for different air pollutants in lag 0 compared with the $<10$ th- group 

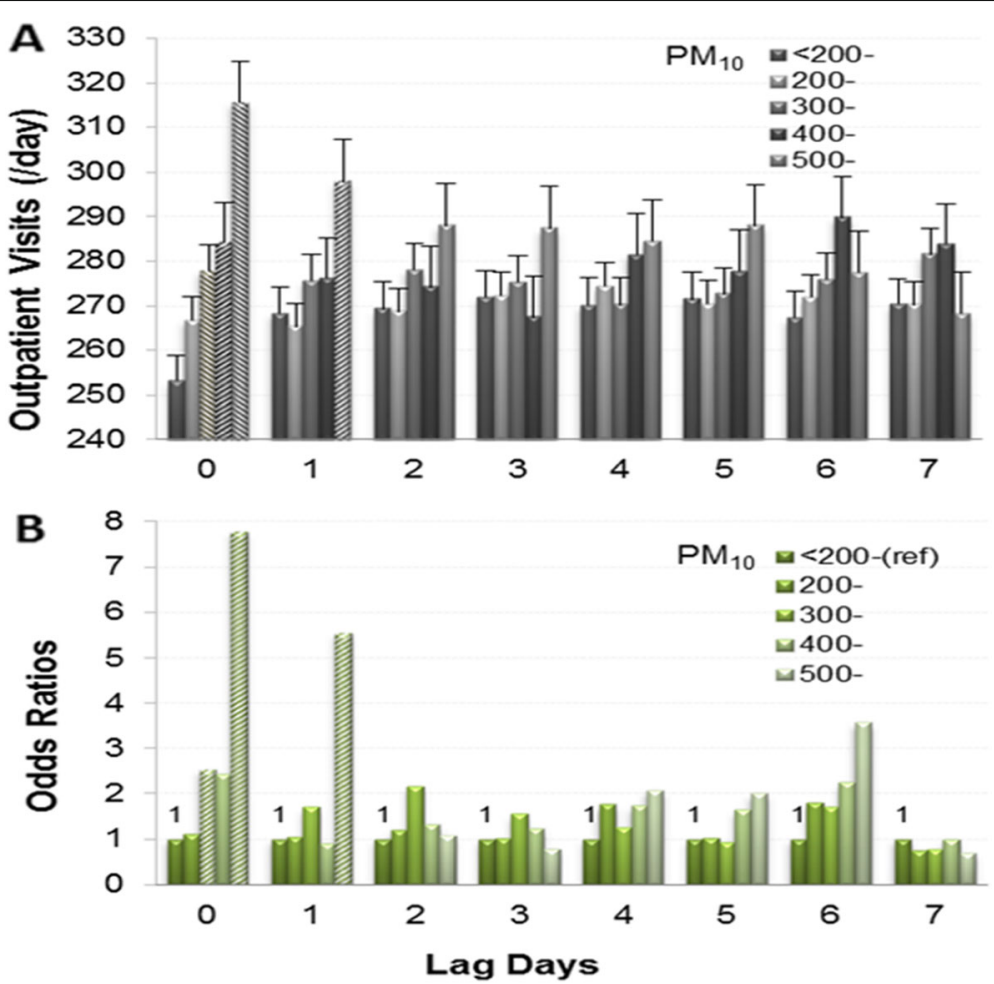

Fig. 2 Relationship between $P M_{10}$ concentration $\left(\mu \mathrm{g} / \mathrm{m}^{3}\right)$ and CVD outpatient visits on different lag days. a: Daily CVD outpatient visits (LSmeans \pm SE). $\mathbf{b}$ : Odds ratios for the increase in daily CVD outpatient visits. A and B were adjusted for days of the week, months, air temperature and relative humidity. Italics indicate significant differences $(P<0.05)$

\section{Impact of CO on CVD outpatient visits}

Figure 4 provides the impact of $\mathrm{CO}$ at different concentrations $\left(\mathrm{mg} / \mathrm{m}^{3}\right)$ and lag days on CVD outpatient visits. In panel $\mathrm{A}$, the LSmeans of lag $0,1,3$ and 4 in the 3 $\mathrm{mg} / \mathrm{m}^{3}$ group were higher than those in the other three groups; the LSmeans of lag 6 in the $2-\mathrm{mg} / \mathrm{m}^{3}$ group and the LSmeans of lag 7 in the $1-\mathrm{mg} / \mathrm{m}^{3}$ group were higher than those in the $<1-\mathrm{mg} / \mathrm{m}^{3}$ group (all $P<0.05$ ). In panel $\mathrm{B}$, the ORs $(95 \% \mathrm{CI})$ of lag 0 in the $1-\mathrm{mg} / \mathrm{m}^{3}, 2$ $\mathrm{mg} / \mathrm{m}^{3}$ and $3-\mathrm{mg} / \mathrm{m}^{3}$ groups were $2.076(0.98-4.396)$, $3.148(0.795-12.473)$ and $5.808(1.016-33.217)$, respectively, and their AR\% were 51.83\%, 68.23 and $82.78 \%$, respectively. Although some LSmeans on other lag days except for lag 0 were significantly higher, the ORs were not significant. Whether LSmeans or ORs, the impact of $\mathrm{CO}$ in the $3-\mathrm{mg} / \mathrm{m}^{3}$ group on CVD was obvious in lag 0.

\section{Impact of $\mathrm{SO}_{2}$ and $\mathrm{NO}_{2}$ on CVD outpatient visits}

However, the increase in daily CVD outpatient visits at different concentrations $\left(\mu \mathrm{g} / \mathrm{m}^{3}\right)$ of $\mathrm{SO}_{2}\left(<50-\mu \mathrm{g} / \mathrm{m}^{3}, 50\right.$ $\mu \mathrm{g} / \mathrm{m}^{3}, 100-\mu \mathrm{g} / \mathrm{m}^{3}$ and $150-\mu \mathrm{g} / \mathrm{m}^{3}$ groups $)$ or $\mathrm{NO}_{2}(<40-$ $\mu \mathrm{g} / \mathrm{m}^{3}, 40-\mu \mathrm{g} / \mathrm{m}^{3}, 70-\mu \mathrm{g} / \mathrm{m}^{3}$ and $100-\mu \mathrm{g} / \mathrm{m}^{3}$ groups) were not as obvious as those of $\mathrm{PM}_{10}, \mathrm{PM}_{2.5}$ and CO. Although the LSmeans in some groups were higher than those in other groups (between the $150-\mu \mathrm{g} / \mathrm{m}^{3}$ and 50 - $\mu \mathrm{g} / \mathrm{m}^{3}$ groups for $\mathrm{SO}_{2}$; between the $100-\mu \mathrm{g} / \mathrm{m}^{3}$ and 40 $\mu \mathrm{g} / \mathrm{m}^{3}$ groups for $\mathrm{NO}_{2}$ ), all ORs for the increase in outpatient visits were not significant (not shown).

\section{Other supplementary analyses}

Additional multiple logistic stepwise regression analyses also showed that $\mathrm{PM}_{2.5}(\mathrm{OR}=2.268, \mathrm{CI}: 1.142-4.504)$ and $\mathrm{CO}(\mathrm{OR}=2.687, \mathrm{CI}: 1.114-6.479)$ were the main risk factors for the increase in daily CVD outpatient visits (not shown). Moreover, Additional file 1: Table S2 also provides the ORs of daily CVD outpatient visits in lag 0 per increase in different units of each pollutant. The results showed that $\mathrm{PM}_{2.5}, \mathrm{PM}_{10}$ and $\mathrm{CO}$ increased the risk of the increase in CVD outpatient visits. $\mathrm{PM}_{2.5}$, $\mathrm{PM}_{10}$ and $\mathrm{CO}$ can be considered the main risk factors according to the results of the ORs and standardized estimates. However, the ORs from $\mathrm{SO}_{2}, \mathrm{NO}_{2}$, and $\mathrm{O}_{3}$ (in 183 days of the warm period) were not significant, and the standardized estimate from $\mathrm{O}_{3}$ (in 365 days) was unexpectedly negative. The trend of results in Additional file 1: Table S2 was consistent with the LSmeans (Table 1), the increased percentage (Fig. 1) and the ORs (B of Fig. 2, 3, 4), although those numerical values were different. Additional file 1: Table S3 provides the Pearson partial correlation coefficient between daily CVD 

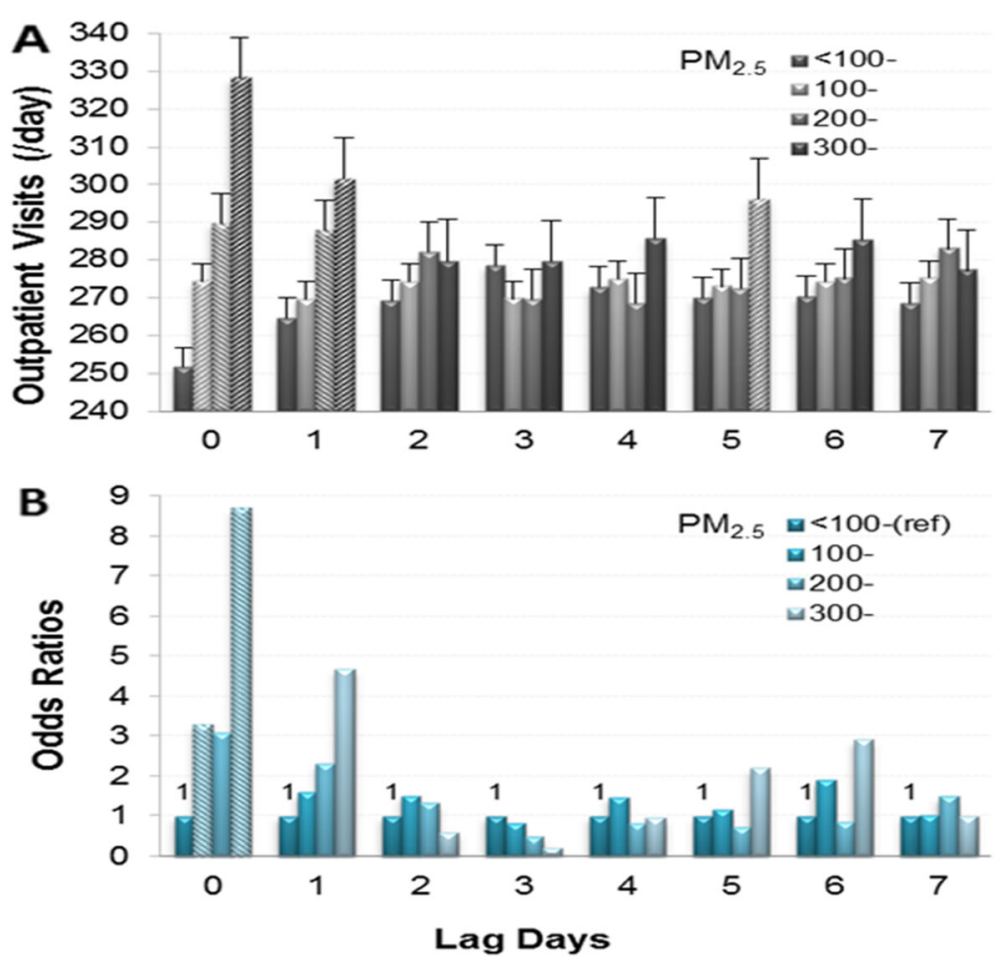

Fig. 3 Relationship between $\mathrm{PM}_{2.5}$ concentration $\left(\mu \mathrm{g} / \mathrm{m}^{3}\right)$ and CVD outpatient visits on different lag days. a: Daily CVD outpatient visits (LSmeans \pm SE). B: Odds ratios for the increase in daily CVD outpatient visits. $\mathbf{a}$ and $\mathbf{b}$ were adjusted for days of the week, months, air temperature and relative humidity. Italics indicate significant differences $(P<0.05)$

outpatient visits and air pollutants on different lag days; the trend of those coefficients was also consistent with results from Table 1, Fig. 1 and Additional file 1: Table S2, and most of the coefficients for $\mathrm{O}_{3}$ (in 365 days) were also negative.

\section{Discussion}

Several epidemiological (observational) studies have shown that hospitalization or death due to acute heart failure is associated with increased concentrations of $\mathrm{PM}_{10}, \mathrm{PM}_{2.5}, \mathrm{CO}, \mathrm{SO}_{2}$, and $\mathrm{NO}_{2}[2-6,8,9]$. However, few published articles have used LSmeans and logistic regression to explore the relationship between acute exposure to air pollutants and increased CVD outpatient visits in a severe haze-fog city. In this study, we evaluated the increased percentage and risk (OR) of the increase in daily CVD outpatient visits for different concentrations of air pollutants using LSmeans and logistic regression. Daily CVD outpatient visits increased by approximately $30 \%$ in the 90th-quantile group $\left(\mathrm{PM}_{10} \geq 535 \mu \mathrm{g} / \mathrm{m}^{3}, \mathrm{PM}_{2.5} \geq 304 \mu \mathrm{g} / \mathrm{m}^{3}, \mathrm{CO} \geq 4.3 \mathrm{mg} / \mathrm{m}^{3}\right)$, which was consistent with the television reports when severe haze-fog occurred. Our results, which were expressed using LSmeans and the increased percentages, should be easier to understand for the general population.

\section{Impact of Particulate Matter}

Many studies have shown that short-term exposure to $\mathrm{PM}_{10}$ or $\mathrm{PM}_{2.5}$ was significantly associated with an increase in hospital admissions for CVD [3-7, 10, 11, 13, 14, 16-23]. $\mathrm{PM}_{10}$ and $\mathrm{PM}_{2.5}$ increased the risk of hospitalization for heart failure $\left(\mathrm{PM}_{10} 1.63 \%\right.$ per $10-\mu \mathrm{g} /$ $\mathrm{m}^{3}$ increase, CI: $1.20-2.07 ; \mathrm{PM}_{2.5} 2.12 \%$ per $10-\mu \mathrm{g} / \mathrm{m}^{3}$ increase, CI: 1.42-2.82). The strongest association was often observed on the day of exposure $[4,10,21] . \mathrm{PM}_{2.5}$ had a stronger impact on heart failure than other cardiovascular diseases, with $3.1 \%$ of heart failure admissions attributable to short-term $\mathrm{PM}_{2.5}$ exposure over background levels of $5 \mu \mathrm{g} / \mathrm{m}^{3}$. Older adults were significantly more susceptible to heart failure than younger adults after short-term $\mathrm{PM}_{2.5}$ exposure [17]. In Beijing, China, after adjustments were made for the temperature and relative humidity, the ORs for CVD in hospital emergency room visits for $10-\mu \mathrm{g} / \mathrm{m}^{3}$ increases in $\mathrm{PM}_{2.5}$ were 1.005 (95\% CI: 1.001-1.009) [7]. In Shanghai, China, a 10- $\mu \mathrm{g} / \mathrm{m}^{3}$ increase in $\mathrm{PM}_{10}$ and $\mathrm{PM}_{2.5}$ in 2 days resulted in an increase of $0.23 \%$ (CI: $0.12-0.34$ ) and $0.74 \%$ (CI: 0.44-1.04), respectively, in the morbidity of coronary heart disease [14]. In our study, $\mathrm{PM}_{10}$ (the 90th-quantile value $\geq 535 \mu \mathrm{g} / \mathrm{m}^{3}$ ) and $\mathrm{PM}_{2.5}$ (the 90th-quantile value $\geq 304 \mu \mathrm{g} / \mathrm{m}^{3}$ ) led to an approximately $30 \%$ increase in daily CVD outpatient visits. The risk of an increase in CVD outpatient visits due to 

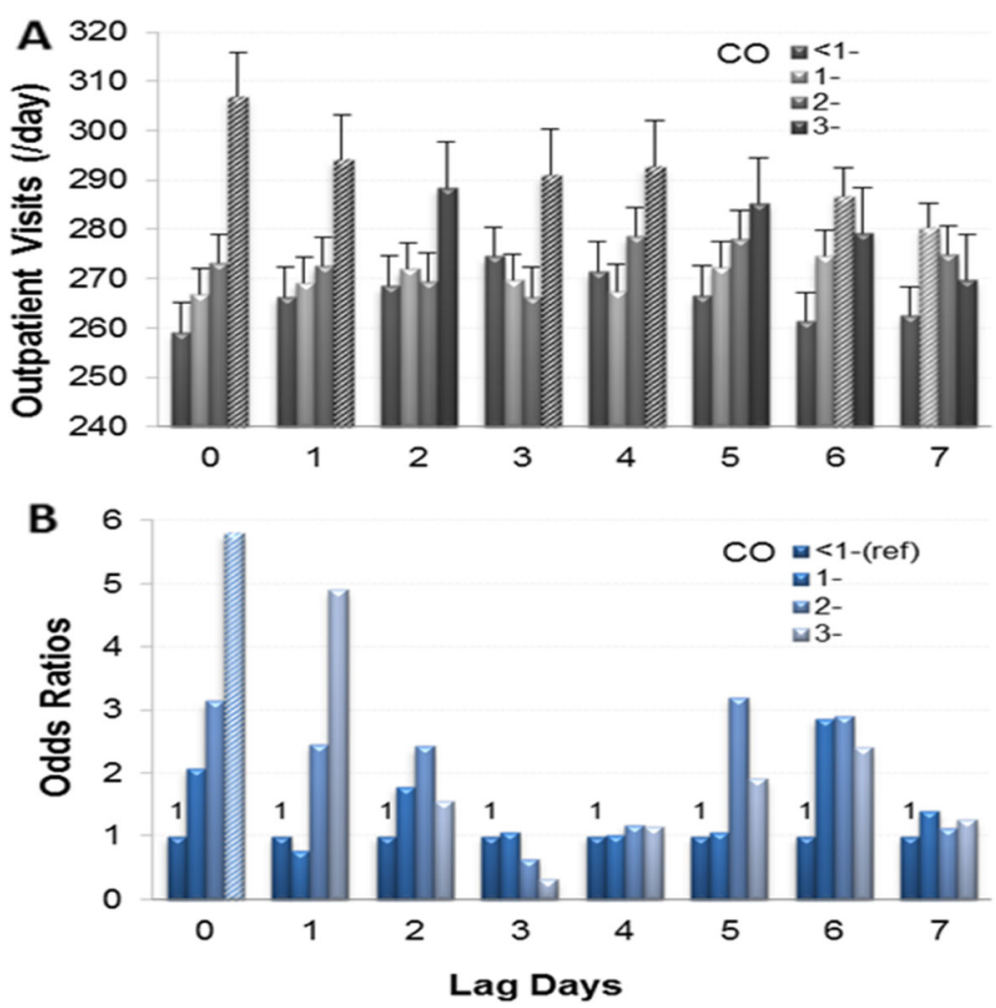

Fig. 4 Relationship between CO concentration $\left(\mathrm{mg} / \mathrm{m}^{3}\right)$ and CVD outpatient visits on different lag days. a: Daily CVD outpatient visits (LSmeans \pm $\mathrm{SE})$. $\mathbf{b}$ : Odds ratios for the increase in daily CVD outpatient visits. $\mathbf{a}$ and $\mathbf{b}$ were adjusted for days of the week, months, air temperature and relative humidity. Italics indicate significant differences $(P<0.05)$

$\mathrm{PM}_{10}\left(\geq 500 \mu \mathrm{g} / \mathrm{m}^{3}\right)$ and $\mathrm{PM}_{2.5}\left(\geq 300 \mu \mathrm{g} / \mathrm{m}^{3}\right)$ reached 7.781 (CI: $1.681-36.024)$ and 8.72 (CI: $1.523-49.934)$, respectively, and their AR\% reached 87.15 and $88.53 \%$, respectively. Although the concentrations of $\mathrm{PM}_{10}$ and $\mathrm{PM}_{2.5}$ and the values of ORs (calculated by different concentrations of air pollutants) in our study were different from those in other studies (usually calculated by an OR per $10-\mu \mathrm{g} / \mathrm{m}^{3}$ increase), our results also revealed that $\mathrm{PM}_{10}$ and $\mathrm{PM}_{2.5}$ had a stronger impact on CVD outpatient visits, and the trend of the impact was similar to that in other studies.

\section{Impact of $\mathrm{SO}_{2}$ and $\mathrm{NO}_{2}$}

The association of $\mathrm{SO}_{2}$ and $\mathrm{NO}_{2}$ with CVD was also the most intensively studied, similarly to $\mathrm{PM}_{10}$ and $\mathrm{PM}_{2.5}$ [3-7, 9, 11, 13, 17, 19-21, 24-27]. Hospitalization or death due to heart failure has been associated with increases in $\mathrm{SO}_{2}$ (2.36\% per $\left.10 \mathrm{ppb}, \mathrm{CI}: 1.35-3.38\right)$ and $\mathrm{NO}_{2}(1.70 \%$ per $10 \mathrm{ppb}, \mathrm{CI}: 1.25-2.16)$ concentrations [10]. These pollutants have been significantly associated with an increase in myocardial infarction risk $\left(\mathrm{NO}_{2}\right.$ : 1.011, CI: 1.006-1.016; $\mathrm{SO}_{2}$ : 1.010, CI: 1.003-1.017) [11]. However, some studies have shown that $\mathrm{SO}_{2}$ made no independent contribution to admissions for ischaemic heart disease, and $\mathrm{SO}_{2}$ became insignificant after controlling for $\mathrm{PM}_{10}$ [5]. On warm days $\left(>25^{\circ} \mathrm{C}\right), \mathrm{SO}_{2}$ had no significant positive associations with congestive heart failure [24]. In our study, daily CVD outpatient visits for $\mathrm{SO}_{2}$ and $\mathrm{NO}_{2}$ were increased only in the higher concentration of the 90th-quantile group $\left(\mathrm{SO}_{2} \geq 228 \mu \mathrm{g} / \mathrm{m}^{3}\right.$, $\left.\mathrm{NO}_{2} \geq 109 \mu \mathrm{g} / \mathrm{m}^{3}\right)$, and the increased percentages $\left(\mathrm{SO}_{2}=\right.$ $\left.17.68 \%, \mathrm{NO}_{2}=14.98 \%\right)$ were lower than those for $\mathrm{PM}_{10}$, $\mathrm{PM}_{2.5}$ and $\mathrm{CO}$ by approximately $50 \%$. All the ORs for the increase in CVD outpatient visits were also insignificant, which revealed that the impact of $\mathrm{SO}_{2}$ and $\mathrm{NO}_{2}$ on CVD may be smaller than that of $\mathrm{PM}_{10}, \mathrm{PM}_{2.5}$ and $\mathrm{CO}$.

\section{Impact of carbon monoxide}

$\mathrm{CO}$ was the earliest-studied gaseous pollutant related to CVD because it can lead to the accumulation of carboxyhaemoglobin and can reduce the oxygen-carrying capacity of the blood $[3-5,9,11,13,17,19-22,24,25$, 27-32]. High concentrations of CO have caused myocardial infarction [33], and low concentrations of $\mathrm{CO}$ have been associated with angina [34, 35]. Many studies have revealed that $\mathrm{CO}$ levels were positively associated with hospital admissions for congestive heart failure in the single-pollutant and multipollutant models [9]. There was a $3.52 \%$ (CI: 2.52-4.54) increase in hospitalizations or mortality due to heart failure per 1-ppm increment of CO [10]. CO was the strongest predictor of 
cardiovascular visits in multipollutant models [20]. In our study, higher $\mathrm{CO}$ in the 90th- quantile group $(\mathrm{CO} \geq$ $4.3 \mathrm{mg} / \mathrm{m}^{3}$ ) led to a $29.34 \%$ increase in daily CVD outpatient visits; the risk of the increase in CVD outpatient visits due to $\mathrm{CO}\left(\geq 3 \mathrm{mg} / \mathrm{m}^{3}\right)$ reached 5.808 (CI: 1.01633.217), and its AR\% reached $82.78 \%$, which revealed that $\mathrm{CO}$ was also a stronger risk factor (similar to $\mathrm{PM}_{10}$ and $\left.\mathrm{PM}_{2.5}\right)$.

\section{Impact of ozone}

$\mathrm{O}_{3}$ was the most controversial air pollutant related to CVD. Several studies have shown that $\mathrm{O}_{3}$ has a positive correlation with CVD [3, 4, 8, 9, 16, 26, 30, 35]. Shortterm inhalation of fine particulate matter and $\mathrm{O}_{3}$ has caused acute conduit artery vasoconstriction [16]. Twopollutant models have indicated that the impact of $\mathrm{O}_{3}$ has been significant in combination with another pollutant on warm days [26]. The OR and 95\% CI estimated from general additive models for an interquartile range increase in $\mathrm{O}_{3}(20.5 \mathrm{ppb})$ was 1.010 (CI: 1.002-1.017) [30]. However, other studies have shown that $\mathrm{O}_{3}$ was not associated with CVD or was negatively correlated [5, $10,11,13,18,19,21]$. All the main air pollutants, with the exception of $\mathrm{O}_{3}$, were significantly associated with an increase in the risk of myocardial infarction; for $\mathrm{O}_{3}$, the relative risk (RR) was 1.003 (CI: 0.997-1.010) [8]. Hospitalization or death due to heart failure was not associated with increases in $\mathrm{O}_{3}$ concentrations $(0.46 \%$ per 10 ppb, CI: - 0.10-1.02) [10]. The RR of admission for ischaemic heart disease and $95 \% \mathrm{CI}$ for interquartile range increases in $\mathrm{O}_{3}$ were $1.010(0.990-1.032)$ [5]. In some studies, the analyses for $\mathrm{O}_{3}$ were restricted to the warm period (May to October) [36]. In our study, $\mathrm{O}_{3}$ levels in 365 days were negatively associated with CVD outpatient visits. However, there was no longer a negative relationship in the 183 days of the warm period, although CVD outpatient visits did not increase substantially. One study from southern China showed that the impact of $\mathrm{O}_{3}$ on CVD mortality was stronger during highexposure months (September to November) after adjustments were made for $\mathrm{PM}_{10}$ [37]; these findings differed from our results. It is well known that $\mathrm{O}_{3}$ is the main component of photochemical smog (85\%) that is the product of $\mathrm{NO}_{2}$ and volatile organic compounds under strong sunlight. The reason for this negative correlation in our study may be that the $\mathrm{O}_{3}$ concentration in Shijiazhuang City was significant different between the winter (for example, $\mathrm{O}_{3}$ averaged $13.6 \mu \mathrm{g} / \mathrm{m}^{3}$, air temperature averaged $-4.2^{\circ} \mathrm{C}$ in January) and the summer $\left(\mathrm{O}_{3}\right.$ averaged $148.5 \mu \mathrm{g} / \mathrm{m}^{3}$, air temperature averaged $24{ }^{\circ} \mathrm{C}$ in Jun), and that the amount of CVD outpatient visits was opposite to the concentration of $\mathrm{O}_{3}$ (averaged 274 people in January, 249 people in June, without adjusting any factors). The impact of air temperature on
CVD outpatient visits was significant, but that of $\mathrm{O}_{3}$ was not significant, and there was no significant interaction between both of them (not shown). The our results after adjusting for air temperature showed an actual relationship between $\mathrm{O}_{3}$ and CVD outpatient visits, which were similar to other studies $[1,5,11,13,18,19,21,36]$. The reason for the difference between the north and the south in China may be that $\mathrm{O}_{3}$ level in winter of Guangzhou was still high $\left(\mathrm{O}_{3}\right.$ averaged $50 \mu \mathrm{g} / \mathrm{m}^{3}$, air temperature $>10{ }^{\circ} \mathrm{C}$ in January) [38], but $\mathrm{O}_{3}$ level in winter of Shijiazhuang was very low (averaged $13.6 \mu \mathrm{g} / \mathrm{m}^{3}$, air temperature averaged $-4.2{ }^{\circ} \mathrm{C}$ in January). Therefore, it should be paid an attention to the difference between the $\mathrm{O}_{3}$ concentration and CVD outpatient visits in the warm and cold periods, especially when there is a negative correlation.

In our supplemental files, whether for the risk of increasing CVD outpatient visits per unit increase of air pollutant or for Pearson partial correlation coefficient between daily CVD outpatient visits and air pollutants, the trend of both results was consistent with the trend of the results from the main table and figures. The supplemental results also revealed that the impact of $\mathrm{PM}_{10}$, $\mathrm{PM}_{2.5}$ and $\mathrm{CO}$ on CVD outpatient visits was stronger than that of $\mathrm{SO}_{2}, \mathrm{NO}_{2}$ and $\mathrm{O}_{3}$.

Our study has three strengths. First, we explored the relationship between the different concentrations of air pollutants and the amount of CVD outpatient visits in a severe haze-fog city using GLM (LSmeans) and logistic regression (ORs). Second, our study revealed that when the concentration of air pollutants increased, an increase was seen not only in the number of CVD outpatient visits but also in the risk of the increase in CVD. Third, although the analytical methods differed from each other, the impacting trend of air pollutants in this study was consistent with those of other studies; specifically, $\mathrm{PM}_{10}, \mathrm{PM}_{2.5}$, and $\mathrm{CO}$ were the main risk factors for the increase in CVD outpatient visits. However, our results also have limitations. First, the climate in northern China (Beijing or Shijiazhuang) and southern China (Shanghai or Guangzhou) varies greatly, and our results for $\mathrm{O}_{3}$ may be different from those of other cities in southern China. Second, because Shijiazhuang is only one of many heavily polluted cities in northern China, our analytical method and results need to be validated in studies of other heavily polluted cities in the future.

\section{Conclusions}

The present study explored the association between daily air pollutants and CVD outpatient visits in a severe haze-fog city in 2013 using GLM (LSmeans) and logistic regression (ORs). Our findings revealed that the elevated concentration of five air pollutants, with the exception of $\mathrm{O}_{3}$, increased the number of CVD outpatient visits 
and that $\mathrm{PM}_{10}, \mathrm{PM}_{2.5}$ and $\mathrm{CO}$ also heightened the risk of the increase in CVD outpatient visits. The trend for the impact of air pollutants on CVD outpatient visits was the same as those of other studies, although the analytical methods were changed in this study. The results of this study will provide a reference for early warnings for managers or physicians in the hospital and the staff of the Centers for Disease Control and Prevention before severe haze-fog occurs.

\section{Supplementary information}

Supplementary information accompanies this paper at https://doi.org/10. 1186/s12889-019-7690-4.

Additional file 1: Figure S1 and Tables S1-S3. Table S2 and S3 provides the ORs of daily CVD outpatient visits in lag 0 per increase in different units of each pollutant, and the Pearson partial correlation coefficient between of them, respectively. These additional results also supported our conclusion.

\section{Abbreviations}

AR\%: Attributable risk percent;; BTH: Beijing-Tianjin-Hebei; Cl: Confidence interval; CO: Carbon monoxide; CVD: Cardiovascular disease; LSmeans: Least squares mean; $\mathrm{NO}_{2}$ : Nitrogen dioxide; $\mathrm{O}_{3}$ : Ozone; ORs: Odds ratios; $\mathrm{PM}_{10}$ and $\mathrm{PM}_{2.5}$ : Particulate matter; $\mathrm{SO}_{2}$ : Sulphur dioxide

\section{Acknowledgements}

We are thankful for the meteorological data support from the National Meteorological Information Center in Beijing and the funding from the Department of Environmental Protection of Hebei Province.

\section{Authors' contributions}

FT was responsible for study design, statistical analysis, manuscript preparation and writing. WW, XY and DW supplied and checked the original data of outpatient visits and air pollutants; SQ and YL checked the results and made tables and figures; HK helped checking manuscript and revising some content; BX, FM and SL verified all data and made preliminary analysis. All authors have read and approved the manuscript.

\section{Funding}

This study was supported by the Public Welfare Program from the Department of Environmental Protection of Hebei Province (2014). The funding body only provided the information on concentration of air pollutants.

\section{Availability of data and materials}

The datasets are available from the corresponding author on reasonable request.

\section{Ethics approval and consent to participate}

We only collected the total number of CVD outpatient visits, and the selection was not related to outpatients' personal privacy (i.e., not including personal name, gender, ethnicity, body weight, etc.), and the data belong to de-identification. The study protocol was approval by Medical Ethics Committee in Hebei Medical University (No.20180062).

\section{Consent for publication}

Not applicable.

\section{Competing interests}

The authors declare that they have no competing interests.

\section{Author details}

'Department of Environmental and Occupational Health, School of Public Health, Hebei Medical University, 361 Zhongshan East Road, Shijiazhuang 050017. Hebei, China. ${ }^{2}$ Departments of Toxicology, School of Public Health, Hebei Medical University, Shijiazhuang, China. ${ }^{3}$ Department of Outpatient
Medical Record, The Second Hospital of Hebei Medical University, Shijiazhuang, China. ${ }^{4}$ School of Public Health, Key Lab of Public Health Safety (Ministry of Education), Fudan University, Shanghai, China. ${ }^{5}$ Hebei Society for Environmental Sciences, Shijiazhuang, China. ${ }^{6}$ Department of of Toxicology, School of Public Health, Hebei Medical University, Shijiazhuang, China.

Received: 16 August 2019 Accepted: 25 September 2019

Published online: 24 October 2019

\section{References}

1. Chen R, Kan H, Chen B, Huang W, Bai Z, Song G, et al. Association of particulate air pollution with daily mortality: The china air pollution and health effects study. Am J Epidemiol. 2012;175:1173-81.

2. Goldberg MS, Burnett RT, Valois MF, Flegel K, Bailar JC III, Brook J, et al. Associations between ambient air pollution and daily mortality among persons with congestive heart failure. Environ Res. 2003;91:8-20.

3. Peel JL, Metzger KB, Klein M, et al. Ambient air pollution and cardiovascular emergency department visits in potentially sensitive groups. Am J Epidemiol. 2007;165:625-33.

4. Metzger KB, Tolbert PE, Klein M, Flanders WD, Mulholland JA, Tolbert PE, et al. Ambient air pollution and cardiovascular emergency department visits. Epidemiology. 2004;15:46-56

5. Schwartz J, Morris R. Air pollution and hospital admissions for cardiovascular disease in Detroit, Michigan. Am J Epidemiol. 1995;142:23-35.

6. Zhao A, Chen R, Kuang X, Kan H. Ambient Air Pollution and Daily Outpatient Visits for Cardiac Arrhythmia in Shanghai, China. J Epidemiology. 2014;24:321-6.

7. Guo Y, Jia Y, Pan X, Liu L, Wichmann HE. The association between fine particulate air pollution and hospital emergency room visits for cardiovascular diseases in Beijing, China. Sci Total Environ. 2009;407:4826-30.

8. Wong CM, Ma S, Hedley AJ, Lam TH. Does ozone have any effect on daily hospital admissions for circulatory diseases? J Epidemiol Community Health. 1999:53:580-1.

9. Morris RD, Naumova EN, Munasinghe RL. Ambient air pollution and hospitalization for congestive heart failure among elderly people in seven large US cities. Am J Public Health. 1995;85:1361-5.

10. Shah AS, Langrish JP, Nair H, Mcallister DA, Hunter AL, Donaldson K, et al. Global association of air pollution and heart failure: a systematic review and meta-analysis. Lancet. 2013;382:1039-48.

11. Mustafić H, Jabre P, Caussin C, Murad MH, Escolano S, Tafflet M, et al. Main air pollutants and myocardial infarction: a systematic review and metaanalysis. JAMA. 2012;307:713-21.

12. Langrish JP, Watts SJ, Hunter AJ, Shah ASV, Bosson JA, Unosson J, et al. Controlled Exposures to Air Pollutants and Risk of Cardiac Arrhythmia. Environ Health Perspect. 2014;122:747-53.

13. Linn WS, Szlachcic Y, Gong H, Kinney PL, Berhane KT. Air pollution and daily hospital admissions in metropolitan Los Angeles. Environ Health Perspect. 2000;108:427-34.

14. Ye X, Peng L, Kan H, Wang W, Geng F, Mu Z, et al. Acute Effects of Particulate Air Pollution on the Incidence of Coronary Heart Disease in Shanghai, China. Plos One. 2016;11(3):e0151119. https://doi.org/10.1371/ journal.pone.0151119.

15. Wang M. Situation and Countermeasures of Influenza in China in 2013. Chin J Prev Med. 2013;47:394-7.

16. Brook RD, Brook JR, Urch B, Vincent R, Rajagopalan S, Silverman F. Inhalation of fine particulate air pollution and ozone causes acute arterial vasoconstriction in healthy adults. Circulation. 2002;105:1534-6.

17. Haley VB, Talbot TO, Felton HD. Surveillance of the short-term impact of fine particle air pollution on cardiovascular disease hospitalizations in New York State. Environ Health. 2009;8:42. https://doi.org/10.1186/1476069X-8-42.

18. Barnett AG, Williams GM, Schwartz J, et al. The effects of air pollution on hospitalizations for cardiovascular disease in elderly people in Australian and New Zealand cities. Environ Health Perspect. 2006;114:1018-23.

19. Wellenius GA, Bateson TF, Mittleman MA, Schwartz J. Particulate air pollution and the rate of hospitalization for congestive heart failure among medicare beneficiaries in Pittsburgh,Pennsylvania. Am J Epidemiol. 2005;161: 1030-6.

20. Tolberta PE, Kleina M, Peelb $\mathrm{J}$, et al. Multipollutant modeling issues in a study of ambient air quality and emergency department visits in Atlanta. J Expo Sci Environ Epidemiol. 2007;17:S29-5. 
21. Stieb DM, Szyszkowicz M, Rowe BH, Leech JA. Air pollution and emergency department visits for cardiac and respiratory conditions: a multi-city timeseries analysis. Environ Health. 2009;8:1-13. https://doi.org/10.1186/1476069X-8-25.

22. Ye F, Piver WT, Ando M, Portier CJ. Effects of temperature and air pollutants on cardiovascular and respiratory diseases for males and females older than 65 years of age in Tokyo, July and August 1980-1995. Environ Health Perspect. 2001;109:355-9.

23. Belleudi V, Faustini A, Stafoggia M, Cattani G, Marconi A, Perucci CA, et al. Impact of fine and ultrafine particles on emergency hospital admissions for cardiac and respiratory diseases. Epidemiology. 2010;21:414-23.

24. Lee IM, Tsai SS, Ho CK, Chiu HF, Yang CY. Air pollution and hospital admissions for congestive heart failure in a tropical city: Kaohsiung, Taiwan. Inhal Toxicol. 2007;19:899-904.

25. Burnett RT, Smith-Doiron M, Stieb D, Cakmak S, Brook JR. Effects of particulate and gaseous air pollution on cardiorespiratory hospitalizations. Arch Environ Health. 1999:54:130-9.

26. Wong TW, Lau TS, Yu TS, Neller A, Wong SL, Tam W. Air pollution and hospital admissions for respiratory and cardiovascular diseases in Hong Kong. Occup Environ Med. 1999;56:679-83.

27. Kwon HJ, Cho SH, Nyberg F, Pershagen G. Effects of ambient air pollution on daily mortality in a cohort of patients with congestive heart failure. Epidemiology. 2001;12:413-9.

28. Allred EN, Bleecker ER, Chaitman BR, Dahms TE, Gottlieb SO, Hackney JD. Short-term effects of carbon monoxide exposure on the exercise performance of subjects with coronary artery disease. N Engl J Med. 1989; 321:1426-32.

29. Bell ML, Peng RD, Dominici F, Samet JM. Emergency hospital admissions for cardiovascular diseases and ambient levels of carbon monoxide: results for 126 United States urban counties, 1999-2005. Circulation. 2009;120:949-55.

30. Morris RD, Naumova EN. Carbon monoxide and hospital admissions for congestive heart failure: evidence of an increased effect at low temperatures. Environ Health Perspect. 1998;106:649-53.

31. Ballester F, Rodríguez P, Iñíguez C, Saez M, Daponte A, Galán I, et al. Air pollution and cardiovascular admissions association in Spain: results within the EMECAS project. J Epidemiol Community Health. 2006;60:328-36.

32. Schwartz J. Air pollution and hospital admissions for heart disease in eight US counties. Epidemiology. 1999;10:17-22.

33. Burnett RT, Dales RE, Brook JR, Raizenne ME, Krewski D. Association between ambient carbon monoxide levels and hospitalizations for congestive heart failure in the elderly in 10 Canadian cities. Epidemiology. 1997;8:162-7.

34. Bersin RM, Chatterjee K, Al A. Metabolic and hemodynamic consequences of sodium bicarbonate administration in patients with heart disease. Am J Med. 1989;87:7-14.

35. Marius-Nunez AL. Myocardial infarction with normal coronary arteries after acute exposure to carbon monoxide. Chest. 1990;97:491-4.

36. Kleinman MT, Davidson DM, Vandagriff RB, Caiozzo V, Whittenberger JL. Effects of short-term exposure to carbon monoxide in subjects with coronary artery disease. Arch Environ Health. 1989:44:361-9.

37. Tao Y, Huang W, Huang X, Zhong L, Lu S, Li Y. Estimated acute effects of ambient ozone and nitrogen dioxide on mortality in the Pearl River delta of southern China. Environ Health Perspect. 2012;120:393-8.

38. Chen Y, Zhang J, Huang Z. Spatial-temporal variation of surface ozone in Guangzhou and Its relations with meteorological factors. Environ Monit China. 2017:33:99-109.

\section{Publisher's Note}

Springer Nature remains neutral with regard to jurisdictional claims in published maps and institutional affiliations.

Ready to submit your research? Choose BMC and benefit from:
- fast, convenient online submission
- thorough peer review by experienced researchers in your field
- rapid publication on acceptance
- support for research data, including large and complex data types
- gold Open Access which fosters wider collaboration and increased citations
- maximum visibility for your research: over 100M website views per year
At BMC, research is always in progress.
Learn more biomedcentral.com/submissions

